\title{
BMJ Open Why do patients with multimorbidity in England report worse experiences in primary care? Evidence from the General Practice Patient Survey
}

\author{
Charlotte A M Paddison, ${ }^{1}$ Catherine L Saunders, ${ }^{2}$ Gary A Abel, ${ }^{1}$ Rupert A Payne, ${ }^{1}$ \\ John L Campbell, ${ }^{3}$ Martin Roland ${ }^{1}$
}

To cite: Paddison CAM, Saunders CL, Abel GA, et al. Why do patients with multimorbidity in England report worse experiences in primary care? Evidence from the General Practice Patient Survey. BMJ Open 2015:5:e006172.

doi:10.1136/bmjopen-2014006172

- Prepublication history and additional material is available. To view please visit the journal (http://dx.doi.org/ 10.1136/bmjopen-2014006172).

Received 21 July 2014 Revised 8 January 2015 Accepted 9 January 2015

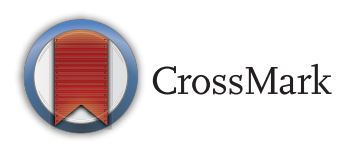

${ }^{1}$ Cambridge Centre for Health Services Research, University of Cambridge, Cambridge, UK ${ }^{2}$ RAND Europe, Cambridge, UK

${ }^{3}$ Department of Primary Care, University of Exeter,

Exeter, UK

Correspondence to Dr Charlotte AM Paddison; camp3@medschl.cam.ac.uk

\section{ABSTRACT}

Objectives: To describe and explain the primary care experiences of people with multiple long-term conditions in England.

Design and methods: Using questionnaire data from 906578 responders to the English 2012 General Practice Patient Survey, we describe the primary care experiences of patients with long-term conditions, including 583143 patients who reported one or more long-term conditions. We employed mixed effect logistic regressions to analyse data on six items covering three care domains (access, continuity and communication) and a single item on overall primary care experience. We controlled for sociodemographic characteristics, and for general practice using a random effect, and further, controlled for, and explored the importance of, health-related quality of life measured using the EuroQoL (EQ-5D) scale.

Results: Most patients with long-term conditions report a positive experience of care at their general practice (after adjusting for sociodemographic characteristics and general practice, range $74.0-93.1 \%$ reporting positive experience of care across seven questions) with only modest variation by type of condition. For all three domains of patient experience, an increasing number of comorbid conditions is associated with a reducing percentage of patients reporting a positive experience of care. For example, compared with respondents with no long-term condition, the $\mathrm{OR}$ for reporting a positive experience is $0.83(95 \% \mathrm{Cl} 0.80$ to 0.87$)$ for respondents with four or more long-term conditions. However, this relationship is no longer observed after adjusting for health-related quality of life $(\mathrm{OR}(95 \% \mathrm{Cl})$ single condition=1.23 (1.21 to 1.26 ); four or more conditions $=1.31$ (1.25 to 1.37)), with pain making the greatest difference among five quality of life variables included in the analysis.

Conclusions: Patients with multiple long-term conditions more frequently report worse experiences in primary care. However, patient-centred measures of health-related quality of life, especially pain, are more important than the number of conditions in explaining why patients with multiple long-term conditions report worse experiences of care.

\section{Strengths and limitations of this study}

- Large national survey with over a million respondents, over half a million with at least one longterm condition.

- Patient experience, morbidity and health-related quality of life all collected in a single survey.

- Thirty-eight per cent response rate, though typical for similar national surveys.

- Measurement of multimorbidity based on counts of self-reported long-term conditions.

\section{INTRODUCTION}

Promoting effective and cost-effective healthcare for people with long-term conditions is an important strategic priority for health policy in the UK and internationally. ${ }^{1-4}$ Approximately 15 million adults with longterm conditions live in the UK, and 6.75 million $(45 \%)$ have more than one long-term condition. ${ }^{5}{ }^{6}$ There is strong and growing interest in how best to provide health services for people with multiple long-term conditions. $^{7-9}$ However, few large quantitative studies have described the primary care experiences of people with multiple longterm conditions, or have examined the relationship between number of long-term conditions and patient experience in primary care.

Measuring patients' experience of care is important because quality of care is a multidimensional construct ${ }^{10}$ and because there is evidence that patient experience can be used to inform improvements in the quality of health services. ${ }^{11}{ }^{12}$ Although there has been considerable recent interest in describing the epidemiology of multimorbidity ${ }^{13}{ }^{14}$ including the association between socioeconomic deprivation and onset of multimorbidity, ${ }^{15}$ there is limited information on the primary care experience of people with more than one long-term condition. People with 
long-term conditions account for $50 \%$ of primary care appointments, $70 \%$ of inpatient bed days, and $70 \%$ of the total health and social care spend in England. ${ }^{6}{ }^{16}$ Those with multiple long-term conditions are more likely to experience poor quality of life, ${ }^{17}$ die prematurely ${ }^{18}$ and be admitted to hospital, ${ }^{19}{ }^{20}$ compared with those with single conditions.

Studies of patient experience to date among people with long-term conditions have tended to focus on single conditions. ${ }^{21}$ In previous work focusing on multimorbidity, an American study found modestly lower measures of doctor-patient communication among people with multiple long-term conditions, ${ }^{22}$ but a study in the UK found no association between multimorbidity and a summary measure of patients' experience. ${ }^{23}$ Definitions of self-care by the UK Department of Health continue to be framed in terms of managing single long-term conditions, ${ }^{24}$ and most clinical guidelines have been developed to support the management of single conditions. ${ }^{14}$ To design health services that improve health for people with multiple longterm conditions, a fresh approach is needed. Primary care-based research may be particularly important; for example, there is evidence of reduced continuity of care in general practices in the $\mathrm{UK},{ }^{25-27}$ but we do not yet know how this fragmentation of care impacts on the health and healthcare experience of patients with multiple long-term conditions.

UK government policy emphasises that peoples' views about their care are central to improving the design and delivery of services. ${ }^{1} 2829$ In order to design better health services for people with multiple long-term conditions, we must attend to some important gaps in our knowledge. We know little about how the primary care experiences of people with multiple long-term conditions compare to the experiences of people with a single long-term condition and, in particular, there is a paucity of research examining the impact of increasing numbers of long-term conditions on patient-reported primary care experience.

This study aims to describe the primary care experiences of people with long-term conditions in England, and to examine the relationship between multimorbidity and patient experience. We address three research questions:

1. How do people with long-term conditions in England describe their experiences of primary care?

2. Among patients with long-term conditions, do those with multimorbidity report better or worse primary care experiences than those with single conditions?

3. Among patients with multiple long-term conditions, how important is quality of life in explaining variation in patient-reported experience?

\section{RESEARCH DESIGN AND METHODS}

Data were collected as part of the 2012 General Practice Patient Survey (GPPS), a national survey of patient experience with primary care sent by mail each year to
2.7 million patients in England who have been continuously registered with a general practice for at least 6 months. Stratified random samples from general practice patient lists-with oversampling of small practices and practices known from prior surveys to provide low response rates-are used to provide an average of 127 respondents per practice. Additional details on the GPPS have been published. ${ }^{30} 31$

\section{Patient experience measures}

A single item was used to measure overall patient experience with primary care services, and six further items were used to measure patient experience in three domains of primary care: access (two questions); continuity of care (one question); and communication (doctor communication (one question with five subitems); nurse communication (one question with five subitems); receptionists, single question). Response options included three-point, four-point and five-point Likert scales. ${ }^{32}$

We used the categorisation employed for the public reporting of these data at the practice level ${ }^{33}$ to define a binary indicator (yes/no) for 'positive experience of care'. For example, for the question on overall experience at your general practice surgery, we considered the endorsement of either 'very good' or 'fairly good' response options to indicate a positive experience of care. For doctor communication and nurse communication, we included respondents who had completed a minimum of three or more of the five constituent subitems, with an overall positive experience defined as endorsement of either 'good' or 'very good' response options for all of the completed items. The specific wording for each survey question in these analyses is provided in table 1.

\section{Demographic and health measures}

The GPPS also includes questions on participants' sociodemographic characteristics. Age was measured using eight ordinal categories from 18-24 to 85+ years. Ethnicity was quantified using categories from the Office of National Statistics (White, Mixed, South Asian, Black, Other). We employed an area-based measure of socioeconomic status based on the patient's residence, categorised into quintiles of increasing socioeconomic deprivation. ${ }^{34}$ Respondents were also asked to indicate, separately, if they had 1 or more of 16 long-term conditions. Health-related quality of life was measured using the five-dimensional EuroQoL (EQ-5D) ${ }^{35}$ which assesses five areas: mobility, self-care, ability to carry out usual activities, pain/discomfort and anxiety/depression.

\section{Analyses}

We described the characteristics of all survey responders with one, two, three, or four or more long-term conditions, accounting for sampling using survey design and non-response weightings. Survey responders with missing data on age, gender, deprivation, ethnicity or the EQ-5D score were excluded from multivariable analyses. 
We first employed mixed effect logistic regressions to examine variation in patient experience by long-term condition using seven patient experience items, while adjusting for age, gender, ethnicity and socioeconomic deprivation using fixed effects, and including a random effect to control for clustering within general practice (hereafter described as controlling for general practice). From these models, we estimated the percentage of respondents who reported a positive experience of care, as defined above, after adjusting for sociodemographic characteristics. Results are reported for all responders with at least one long-term condition, and separately for responders with each of the 16 long-term conditions included in this paper (as a single condition, without comorbidities). Additional models were used to estimate the percentage of respondents reporting a positive experience of care for those with a single long-term condition and, separately, for those with more than one long-term condition.

The second set of analyses employed mixed effect logistic regressions to model the relationship between multimorbidity and patient experience. In these models, comorbidity was included in the form of a count of selfreported long-term conditions (ie, 1, 2, 3, 4 or more coexisting conditions), and a joint (Wald) test was used to evaluate the evidence for overall association with patient experience. A further series of models were used to examine changes in the relationship between number of long-term conditions and patient experience after additional adjustment for health-related quality of life measured using the EQ-5D. We included all EQ-5D domains as separate categorical variables in order to determine which aspect of quality of life was most important in explaining the relationship between multimorbidity and patient experience. Results are presented as ORs, which represent the likelihood of reporting a positive patient experience compared with respondents without any long-term conditions.

\section{Sensitivity analyses}

We compared our results from models adjusting for EQ-5D domains separately as categorical variables and also with those from models adjusting for the EQ-5D health utility state as a continuous measure. As a further sensitivity analysis, we also ran a series of models controlling for mental health. We explored the effect of adjusting our findings for reporting a long-term mental health condition, or anxiety or depression, and we also explored whether the association between multimorbidity and patient experience was different among people with a long-term mental health condition, compared with those without. In an additional sensitivity analysis, we ran a modelling approach which took into account the effect of each condition and combination of conditions, using fixed effects and interactions. Finally, we performed a sensitivity analysis with an alternative outcome definition comparing 'very good' survey responses with all others, and a further sensitivity analysis using imputation for missing data.

\section{RESULTS}

There were 1037946 responses to the 2011-2012 GPPS received from patients registered with 8258 primary care practices (37.8\% survey response rate). Of these, 906578 respondents provided an answer to the question about long-term conditions, including 583143 people

Table 1 Item content for seven questions from the General Practice Patient Survey 2012 evaluating three domains of care (access, continuity and communication), and overall patient experience

\begin{tabular}{|c|c|}
\hline Domain of care & $\begin{array}{l}\text { General Practice Patient Survey item content full wording } \\
\text { (Synoptic form) }\end{array}$ \\
\hline Access & $\begin{array}{l}\text { Generally, how easy it is to get to get through to someone at your GP surgery on the phone? } \\
\text { (Phone access) }\end{array}$ \\
\hline Access & $\begin{array}{l}\text { Overall, how would you describe your experience of making an appointment? } \\
\text { (Making appointment) }\end{array}$ \\
\hline Continuity & $\begin{array}{l}\text { How often to you see or speak to the GP you prefer (answered only by those who had a preference } \\
\text { to see or speak to a particular doctor) } \\
\text { (Seeing preferred doctor) }\end{array}$ \\
\hline $\begin{array}{l}\text { Communication } \\
\text { (non-clinical) }\end{array}$ & $\begin{array}{l}\text { How helpful do you find the receptionists at your GP surgery? } \\
\text { (Receptionist communication) }\end{array}$ \\
\hline $\begin{array}{l}\text { Communication } \\
\text { (doctor) }\end{array}$ & $\begin{array}{l}\text { Last time you saw or spoke to a GP, how good was that GP at each of the following? } \\
\text { Giving you enough time; listening to you; explaining tests and treatments; involving you in decisions } \\
\text { about your care; treating you with care and concern (five-item composite) } \\
\text { (Doctor communication) }\end{array}$ \\
\hline $\begin{array}{l}\text { Communication } \\
\text { (nurse) }\end{array}$ & $\begin{array}{l}\text { Last time you saw or spoke to a nurse, how good was that nurse at each of the following? } \\
\text { Giving you enough time; listening to you; explaining tests and treatments; involving you in decisions } \\
\text { about your care; treating you with care and concern (five-item composite) } \\
\text { (Nurse communication) }\end{array}$ \\
\hline Overall experience & $\begin{array}{l}\text { Overall, how would you describe your experience of your GP surgery? } \\
\text { (Overall experience) }\end{array}$ \\
\hline
\end{tabular}


who reported one or more coexisting long-term condition (see online supplementary appendix figure S1).

Demographic and health characteristics of all respondents are presented in table 2, overall and separately by number of reported conditions. Patients with increasing numbers of long-term conditions were older and reported poorer health-related quality of life. Although the prevalence of a single long-term condition was similar in deprived and non-deprived individuals (approximately $20 \%$ ), multimorbidity was substantially more common among patients living in deprived areas. Among those with four or more long-term conditions, $12.9 \%$ live in the most affluent areas, and $29.6 \%$ in the most deprived.

\section{Patient experience among people with long-term conditions}

Most patients with long-term conditions report a positive experience of care at their general practice (range 74.0$93.1 \%$ reporting positive experience of care across seven questions after adjusting for sociodemographic characteristics; results shown in table 3 , regression coefficients shown in online supplementary appendix table S1). Among people with a single long-term condition, there was modest variation in experience between conditions. For the item measuring overall patient experience in their general practice, $88.3 \%$ of respondents with back pain and $89.0 \%$ with a long-term neurological problem reported positive experiences, compared with $92.8 \%$ with high blood pressure and $94.0 \%$ with learning difficulties. Similar variation in experience across conditions was seen for questions about access and communication (table 3 ). For the item measuring continuity of care, the relationship was less consistent, and notably, $80.8 \%$ survey respondents with long-term mental health problems report being able to see their preferred doctor, compared with less than $70 \%$ of respondents with asthma, learning difficulties, back pain, hearing impairments/deafness or visual impairment/blindness.

\section{Patient experience among people with multimorbidity}

On average, patients with multimorbidity reported poorer experience of primary care for access and communication domains of patient experience, and overall, with between $1.1 \%$ and $2.4 \%$ fewer respondents reporting a positive experience than respondents with a single long-term condition. However, patients with multimorbidity report that they are more likely to see their preferred doctor than patients with a single long-term condition as shown in table 4 (regression coefficients in online supplementary appendix table S2).

\section{The relationship between increasing numbers of long-term} conditions, health-related quality of life and patient experience

We explored the relationship between number of conditions and patient experience and present the results in figure 1A. For patient experience in both access and communication domains, and for overall reported experience, there is a relationship showing that an increase in the number of comorbid conditions is associated with less frequent positive patient experience of care. For example, when compared with respondents with no long-term condition, people with a single long-term condition are slightly more likely to report a positive overall experience of care $(\mathrm{OR}=1.06,95 \%$ CI 1.04 to 1.08), and people with four or more long-term conditions are less likely to report a positive experience of care $(\mathrm{OR}=0.83,95 \%$ CI 0.80 to 0.87$)$. However, this relationship is no longer observed after adjusting for health-related quality of life; ORs for a positive overall experience of primary care were 1.23 (95\% CI 1.21 to 1.26 ) and 1.31 (95\% CI 1.25 to 1.37), for one and four or more conditions, respectively. In comparison to respondents with no long-term conditions and after adjusting for health-related quality of life, all respondents with one or more long-term condition more often reported positive experiences of primary care (figure 1B). All respondents with long-term conditions are more likely to report better continuity of care than those without a long-term condition, even before adjusting for health-related quality of life.

Sensitivity analyses found that adjusting for the EQ-5D domain of pain alone had a comparable impact on the relationship between number of conditions and patient experience (figure 1C, coefficients in online supplementary appendix table S3) as the impact of adjusting for EQ-5D as a complete measure (all five subscales) as shown in figure 1B. Sensitivity analyses also showed that controlling for mental health made no difference to the interpretation of results, nor excluding people with longterm back problems (see online supplementary appendix table S4). Modelling multimorbidity using a more complex approach (see online supplementary appendix figure S2) made no difference to the interpretation of results; for parsimony and ease of interpretation, we elect to present results from analyses that include multimorbidity modelled as a count of long-term conditions in this paper. Findings from the sensitivity analysis which compared reporting 'very good' care to all other responses gave a somewhat different picture to the main analysis. Before adjusting for health-related quality of life, people with long-term conditions were more likely to report 'very good' experiences of care (see online supplementary appendix table S5). Thus, scores from this group were polarised with respondents more likely to report both negative and very positive experiences. Multiple imputation for missing data made no differences to our findings (see online supplementary appendix table $\mathrm{S} 6$ ).

\section{DISCUSSION}

In a study of 906578 patients in England, after controlling for age, gender, socioeconomic status, ethnicity and general practice, those with multiple long-term conditions were found to report positive experiences in 


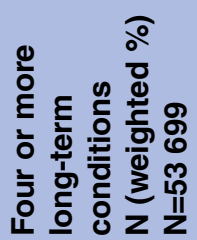

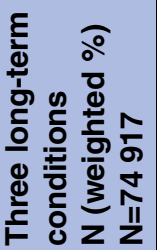

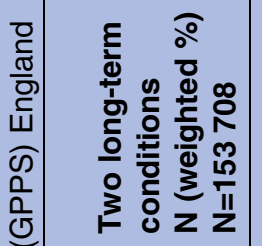

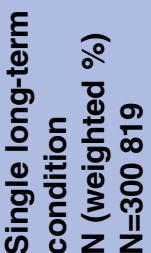
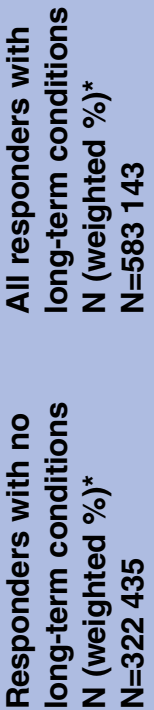

ธุด

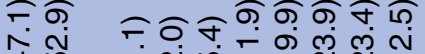

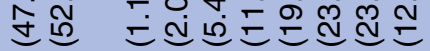

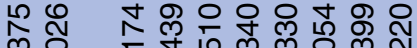

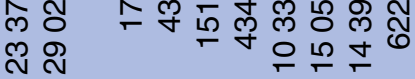

๓ฺก

ปิ กิ

○

लำ

ธิธิ์

守

సิ กิ

$\infty$

กิ

ำ จ

ले

ले

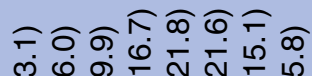

$100 \%$

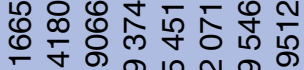

드 พ พ

कุ ซึิ

Бํํํำ

œ స

守

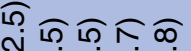

ภู่ ฮู่

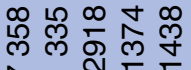
ט

๓ฺ் ๘๐ बढ ภ ำ 仓ิ 당 요

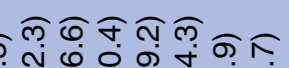

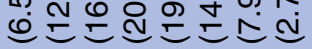

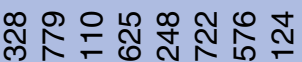

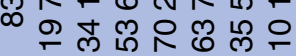

เุ่ สิ กิ

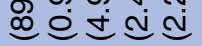

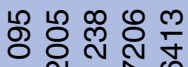

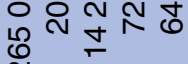

ดิธิธิธ ชิ

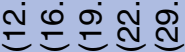

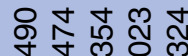

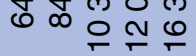

\begin{tabular}{|c|c|}
\hline लొ & $\underset{\infty}{\overparen{\infty}}$ \\
\hline $\begin{array}{l}\text { O } \\
\text { ㄱ } \\
\text { I }\end{array}$ & 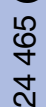 \\
\hline
\end{tabular}

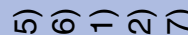

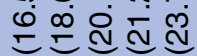
ஜ $\mp \stackrel{m}{\square} \stackrel{\sim}{\leftarrow} \stackrel{\infty}{\square}$

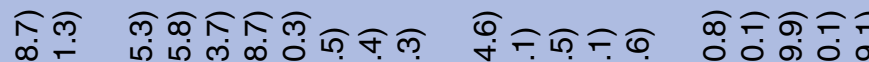

の๐ิกิธ œ

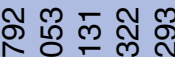
సิ ल సิ 유 ले

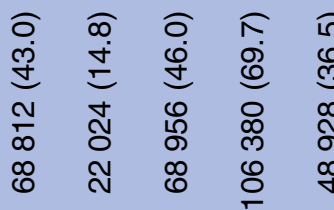

กิก

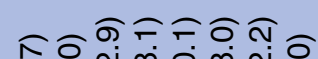

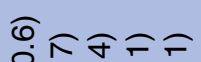
ริกิธิศ อ

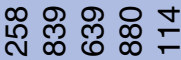

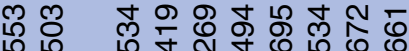
$\infty \frac{m}{n}$

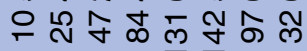
뇨 유 용 요 ㄷำ

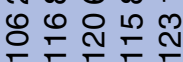

เิจ กิ

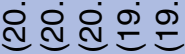
워ำ ํํำ ชิ ชู ชิ

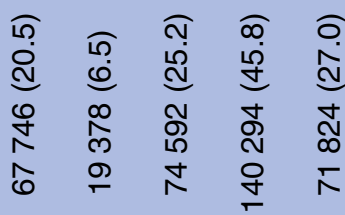

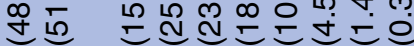
ชิ 응 $\infty$ 定

苛

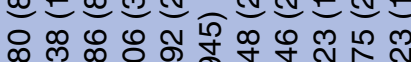
ต

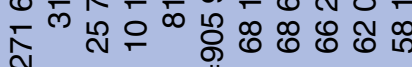

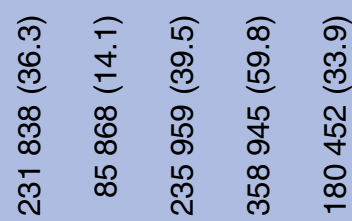

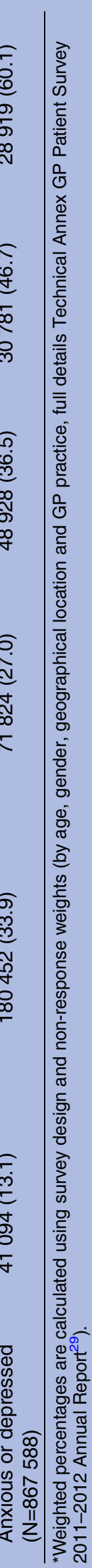


Table 3 Predicted percentages* of positive patient experience by long-term condition

Overall \% reporting a positive experience

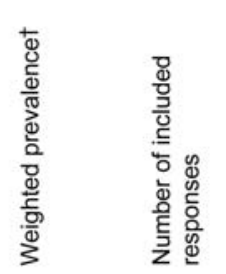

808,095

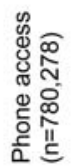

84.8

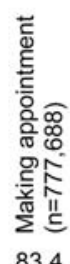

83.4

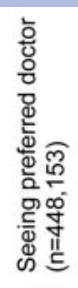

72.1

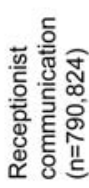

93.2
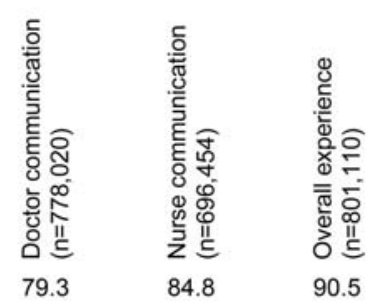

$84.8 \quad 90.5$

\begin{tabular}{|c|c|c|c|c|c|c|}
\hline 87.7 & 88.9 & 69.8 & 95.9 & 83.7 & 87.4 & 94.0 \\
\hline 86.5 & 86.0 & 75.8 & 94.2 & 82.4 & 86.2 & 92.8 \\
\hline 87.1 & 85.9 & 74.9 & 93.6 & 82.2 & 87.7 & 92.6 \\
\hline 85.8 & 85.2 & 74.6 & 93.6 & 82.3 & 86.4 & 92.3 \\
\hline 86.8 & 85.4 & 73.3 & 94.0 & 81.2 & 84.5 & 92.1 \\
\hline 85.7 & 84.9 & 80.8 & 94.0 & 81.0 & 82.6 & 92.1 \\
\hline 85.6 & 84.7 & 74.3 & 93.4 & 81.9 & 85.9 & 91.2 \\
\hline 84.6 & 83.2 & 69.0 & 92.8 & 79.7 & 86.2 & 91.0 \\
\hline 86.9 & 83.6 & 70.6 & 94.0 & 80.6 & 85.1 & 90.7 \\
\hline 84.7 & 83.2 & 70.4 & 93.4 & 78.8 & 84.7 & 90.6 \\
\hline 85.0 & 83.3 & 68.8 & 93.8 & 76.6 & 83.6 & 90.2 \\
\hline 83.1 & 82.6 & 67.6 & 93.4 & 78.4 & 84.5 & 89.9 \\
\hline 86.1 & 84.1 & 72.2 & 92.7 & 79.0 & 83.5 & 89.6 \\
\hline 84.3 & 82.2 & 73.5 & 92.5 & 77.5 & 82.8 & 89.3 \\
\hline 84.6 & 83.5 & 76.4 & 92.6 & 78.6 & 82.0 & 89.0 \\
\hline 82.7 & 81.0 & 68.6 & 92.4 & 75.4 & 82.3 & 88.3 \\
\hline
\end{tabular}

Learning difficulty

High blood pressure Diabetes

Angina or long-term heart problem Epilepsy

Long-term mental health problem

Cancer in the last 5 years

Asthma or long-term chest problem

Alzheimer's disease or dementia

Arthritis or long-term joint problem

Blindness or severe visual impairment

Deafness or severe hearing impairment Kidney or liver disease

Another long-term condition Long-term neurological problem Long-term back problem

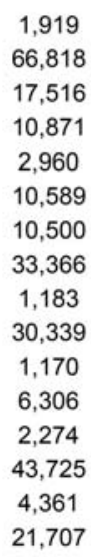

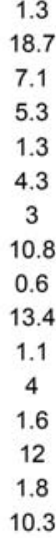

10.3

8.7

7.1

5.3

4.3

3

10.8

1.1

4

6

12
21,707

82.7

505,158

84.7

83.4

74.0

93.1

79.3

84.4

90.7

The responses in this table for each condition are restricted to people with a single long-term condition, allowing comparisons in experience between conditions; as a benchmark, findings from all included responses are given at the top, and all responses from people with long-term conditions at the bottom of the table. Colour code from dark blue (higher predicted percentage of patients with a positive patient experience) to white (lower predicted percentage), by question, and conditions sorted by the percentage endorsing a positive experience to the 'Overall experience' question.

*These percentages are predicted from multivariable logistic regression models to give the percentage of responders expected to report a positive experience should they have the same age, gender, ethnicity and socioeconomic composition as all included survey responders (this percentage is also known as recycled predictions); full results from these models available in online supplementary appendix table $\mathrm{S} 1$.

†Validation available on request from the study authors, estimation based on all survey responders.

primary care less often, when compared with patients with a single condition or with those with no long-term conditions. Health-related quality of life-particularly in the domain of 'pain'-was important in explaining why patients with multiple long-term conditions report worse primary care experiences.

\section{Primary care experience among people with long-term conditions in England}

Our study builds on what is already known about the epidemiology of multimorbidity, ${ }^{13}{ }^{14}$ by investigating the patient experience of people with multiple long-term conditions in primary care. In the USA, quality of care,

Table 4 Primary care experience among patients with a single condition, and multiple long-term conditions

\begin{tabular}{|c|c|c|c|c|c|}
\hline & \multicolumn{3}{|c|}{ Percentage reporting a positive experience of care* } & \multirow[b]{2}{*}{ OR $(95 \% \mathrm{Cl})$} & \multirow[b]{2}{*}{ p Value } \\
\hline & $\begin{array}{l}\text { Single long-term } \\
\text { condition } \\
(\mathrm{n}=265604)\end{array}$ & $\begin{array}{l}\text { More than one } \\
\text { long-term condition } \\
(n=239554)\end{array}$ & $\begin{array}{l}\text { Adjusted } \\
\text { difference (\%) }\end{array}$ & & \\
\hline Phone access & 85.2 & 83.4 & -1.7 & $0.86(0.84$ to 0.88$)$ & $<0.0001$ \\
\hline Making appointment & 83.9 & 81.5 & -2.4 & $0.83(0.81$ to 0.85$)$ & $<0.0001$ \\
\hline Seeing preferred doctor & 73.2 & 74.4 & 1.1 & 1.07 (1.04 to 1.09$)$ & $<0.0001$ \\
\hline Receptionist communication & 93.3 & 92.2 & -1.1 & $0.85(0.82$ to 0.88$)$ & $<0.0001$ \\
\hline Doctor communication & 79.8 & 77.7 & -2.1 & $0.88(0.86$ to 0.89$)$ & $<0.0001$ \\
\hline Nurse communication & 84.9 & 83.3 & -1.6 & $0.88(0.86$ to 0.90$)$ & $<0.0001$ \\
\hline Overall experience & 91.0 & 89.6 & -1.3 & 0.85 (0.83 to 0.88$)$ & $<0.0001$ \\
\hline
\end{tabular}



number of long-term conditions and patient experience in primary care adjusted for sociodemographic characteristics $(A)$ additionally B) and adjusting for sociodemographic characteristics and for the 'Pain' domain of EQ-5D only (instead of the full EQ-5D scale; C).
Figure 1 Relationship between adjusting for the EuroQoL (EQ-5D;

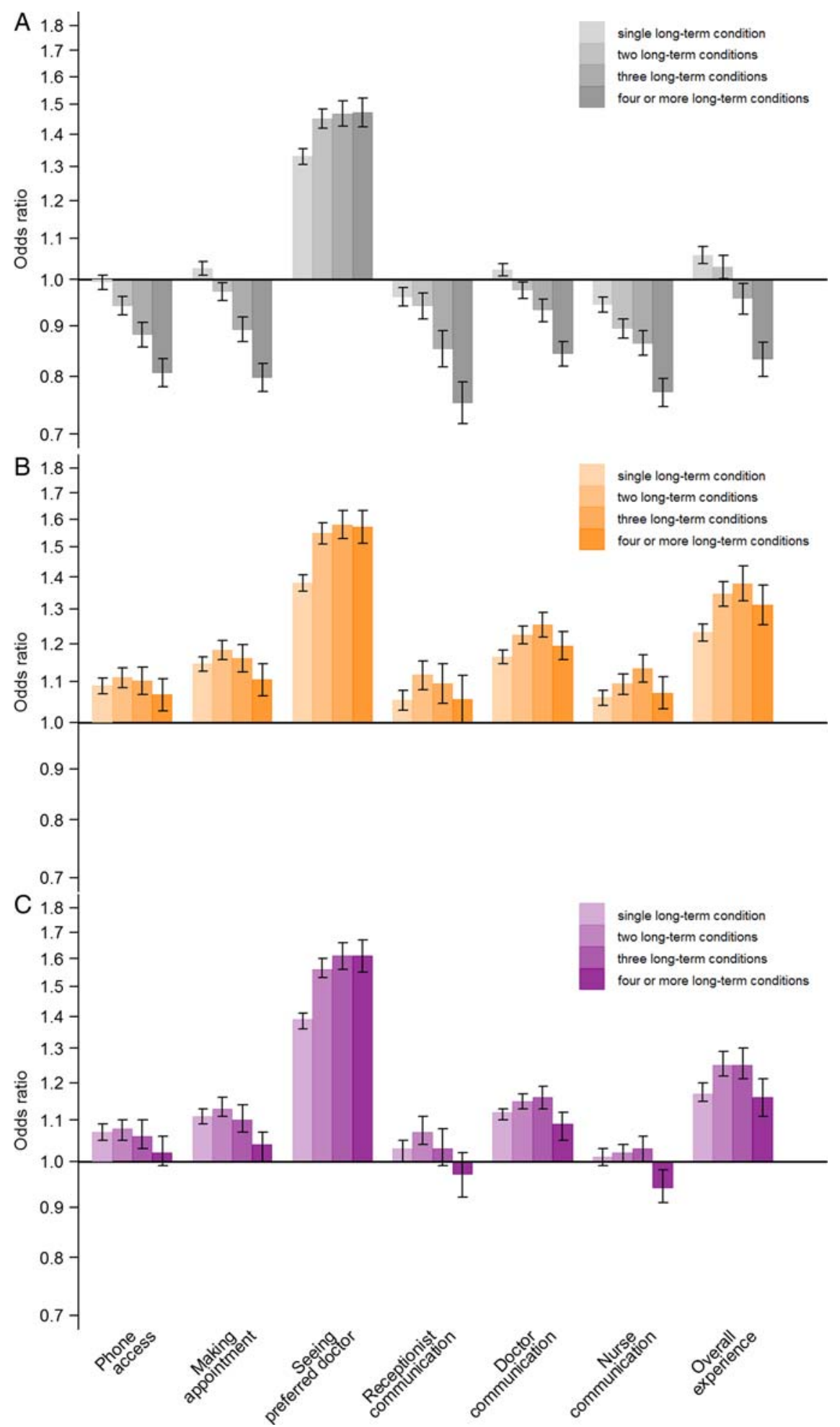

measured in terms of whether patients were offered recommended services, has been shown to increase as a patients' number of long-term conditions increases. ${ }^{36} \mathrm{In}$ a smaller UK study of 2439 patients with long-term conditions, those with higher numbers of coexisting longterm conditions did not report poorer experiences of care, when quantified in terms of patient activation, delivery system, decision support, goal setting and co-ordination. ${ }^{23}$ Our findings, using national survey data from 583143 people with one or more long-term conditions, add to emerging evidence on the complex relationship between multimorbidity and the patients' experience of care by demonstrating a relationship between increasing number of long-term conditions, and poorer patient-reported experience in primary care. This work explores patient experience measures across three domains of care (access, communication and continuity); the findings for communication are consistent 
with previous work from the USA. ${ }^{22}$ Furthermore, this study extends our understanding of the relationship between multimorbidity and patient experience, by suggesting that patients with multiple long-term conditions less often report positive patient experience in primary care not simply because of the number of conditions they have, but because they are more likely to experience pain and have poor health-related quality of life.

\section{Strengths and limitations}

Particular strengths of our study are the large sample size and use of data collected as part of a national survey, and our analysis of the impact of health-related quality of life in addition to number of conditions. This study also has some limitations. We were reliant on patients to report whether they had a long-term condition, and there is no opportunity to verify this or to supplement clinical details through examination of medical records due to the protection of anonymity of survey responders guaranteed by the UK Department of Health. Related to this, the specific list of conditions included in this survey (eg, the grouping of all cardiac problems into one item), and the inclusion of only 16 long-term conditions in our definition of multimorbidity may influence our findings. ${ }^{37}$ We do not expect this to change our conclusions, however. Previous work found that the prevalence of long-term conditions from this survey was moderately consistent with other population sources. ${ }^{38}$ Additionally, although considering mortality and consultation rates, rather than patient experience outcomes, previous work has found relationships with multimorbidity to be consistent across measures and definitions. ${ }^{39}$

Another limitation is the modest response rate to the survey $(38 \%)$. However, in our previous analysis of two questions associated with payment to practices, we found minimal evidence of non-response bias. ${ }^{40}$ Additionally, a meta-analysis of survey methodology literature found that response rates are only a weak predictor of nonresponse bias among studies employing methodology similar to ours. ${ }^{41}$

A limitation of cross-sectional survey research is that all measures are collected at the same time and question ordering within the survey can also influence responses. In this work, patient experience, long-term conditions and health-related quality of life (EQ-5D) are measured concurrently, and in this order, the later appearance of the EQ-5D scale could explain part of the missing data for this item. ${ }^{42}$ It may also be that responses about patient experience items, which appear early, could influence reporting of later questions about health. We acknowledge the potential, but unquantified, effect of the somewhat more subjective EQ-5D questions being presented after questions relating to long-term conditions. Any influence of the long-term condition questions on responses to the EQ-5D questions may lead to a spurious attenuation of the effect of interest when adjusting for EQ-5D. However, given that the direction of association reverses in most cases rather than simply attenuating, we believe this concern is minimal.

\section{Why do people with multimorbidity report worse experience in primary care?}

Patient-centred measures of disease impact, particularly the impact of pain on health-related quality of life, are important in understanding the relationship between number of comorbid conditions and patient experience. We show that the relationship between the number of comorbid conditions and patient experience attenuates substantially when adjusting for health-related quality of life. There are a number of possible explanations for this finding.

First, the impact of disease on quality of life may manifest itself in terms of disability, which in turn affects the patient's experience of primary care. For example, hearing disability affects communication and may have an adverse impact when booking an appointment (access) and when describing the nature of symptoms (doctor-patient communication). Rather than emphasising the importance of number of conditions as the primary driver of differences in patient experience among people with long-term conditions, our results suggest a more patient-centred model that highlights the severity of disease, and the impact of combinations of diseases, on patient's quality of life.

Second, people who have long-term conditions, particularly those that involve somatic pain, may report different experiences of care not because the care they receive is systematically better or worse, but because differences in perception-influenced by pain or depression-may affect the way patients' report their experiences of primary care. This hypothesis is supported by experimental evidence showing that pain influences the encoding and retrieval of events in memory. ${ }^{43} 44$

Third, people with multiple long-term conditions may have different and more complex needs than those with single or no long-term conditions. ${ }^{723}$ These needs are not well served by a system of healthcare delivery that is informed by evidence-based guidelines designed for patients with a single condition, ${ }^{14} 45-48$ and health policy which is framed around the management of a single condition. ${ }^{7813}$ A 10 min appointment, standard in many general practices in England, may be inadequate for a patient with multiple long-term conditions and complex care needs. Patients in some surgeries are specifically requested to limit their appointment to one condition/medical query, and to make a second appointment for any further conditions. Such organisational practices are unlikely to be conducive to a positive patient experience, and can result in a very fragmented experience of care and increased burden of treatment ${ }^{49} 50$ for the patient who is required to make multiple appointments.

Finally, our sensitivity analysis considering an alternative definition of positive experience of care found that 
people with long-term conditions are in fact more likely to report 'very good' experiences, while at the same time being more likely to report negative experiences. Comparing this to our main findings, it would appear that people with multiple long-term conditions may be more polarised in reporting their experiences of care. A possible explanation for this finding is that people with multiple long-term health conditions have more interactions with primary care than other people and this higher frequency of interactions might result in more variation in reported experience. Alternatively, it may be that the complex needs of those with long-term conditions lead to an increase in both the best and worst experiences.

\section{Implications for research, policy and clinical practice}

Health policymakers should recognise that the patient experience and healthcare needs of people with multimorbidity are likely to be different to those with a single long-term condition, and should take this into account when designing health services for people with multiple long-term conditions. We recommend that research modelling the relationship between multimorbidity and patient experience of care should include the impact of health-related quality of life. Further research examining variation in patient experience among people with multiple long-term conditions is needed to identify specific combinations of disease that are more likely to be associated with poor patient experience which could help to inform interventions which aim to improve patient experience among those with multiple long-term conditions. Such research should also take into account the potential impact of concordant, discordant and dominant disease combinations on the experience of care. ${ }^{51}$ Primary care clinicians are encouraged to consider the impact of disease on health-related quality of life, and to understand the potential impacts of pain and functional disability on patient experiences for people with multiple long-term conditions.

\section{Twitter Charlotte Paddison at @CAM_Paddison}

Contributors All authors (CAMP, CLS, GAA, RAP, JLC and MR) jointly conceived of the research questions, reviewed/edited the manuscript and contributed to discussion. CAMP led on writing the manuscript. CLS and GAA completed the statistical analysis. All authors (CAMP, CLS, GAA, RAP, JLC and MR) had full access to all of the data in the study and take responsibility for the integrity of the data and accuracy of the data analysis. MR is the guarantor of the paper.

Funding This research received no specific grant from any funding agency in the public, commercial or not-for-profit sectors.

Competing interests MR and JLC have acted as advisers to the English Department of Health in the development of the General Practice Patient Survey

Provenance and peer review Not commissioned; externally peer reviewed.

Data sharing statement No additional data are available.

Open Access This is an Open Access article distributed in accordance with the Creative Commons Attribution Non Commercial (CC BY-NC 4.0) license, which permits others to distribute, remix, adapt, build upon this work non- commercially, and license their derivative works on different terms, provided the original work is properly cited and the use is non-commercial. See: http:// creativecommons.org/licenses/by-nc/4.0/

\section{REFERENCES}

1. Department of Health. Equity and excellence: liberating the NHS, 2010. https://www.gov.uk/government/uploads/system/uploads/attachment_ data/file/213823/dh_117794.pdf (accessed 21 Nov 2014).

2. Department of Health. Health and Social Care Act. UK, 2012. http:// www.legislation.gov.uk/ukpga/2012/7/contents/enacted (accessed 21 Nov 2014).

3. Wagner EH, Austin BT, Davis C, et al. Improving chronic illness care: translating evidence into action. Health Aff 2001;20:64-78.

4. Bayliss EA, Bonds DE, Boyd CM, et al. Understanding the context of health for persons with multiple chronic conditions: moving from what is the matter to what matters. Ann Fam Med 2014;12:260-9.

5. Department of Health. Raising the profile of long term conditions care. Leeds, UK: DH, 2008. http://webarchive.nationalarchives.gov. uk/20130107105354/http:/www.dh.gov.uk/prod_consum_dh/groups/ dh_digitalassets/documents/digitalasset/dh_082067.pdf (accessed 21 Nov 2014).

6. Department of Health. Long term conditions compendium of information. Leeds, UK: DH, 2012. https://www.gov.uk/government/ uploads/system/uploads/attachment_data/file/216528/dh_134486.pdf (accessed 21 Nov 2014).

7. Salisbury C. Multimorbidity: redesigning health care for people who use it. Lancet 2012;380:7-9.

8. Department of Health. Comorbidities: a framework of principles for system-wide action, 2014. https://www.gov.uk/government/uploads/ system/uploads/attachment_data/file/307143/Comorbidities_ framework.pdf (accessed 21 Nov 2014).

9. Goodman RA, Boyd C, Tinetti ME, et al. IOM and DHHS meeting on making clinical practice guidelines appropriate for patients with multiple chronic conditions. Ann Fam Med 2014;12:256-9.

10. Llanwarne N, Abel GA, Elliott M, et al. Relationship between clinical quality and patient experience: analysis of data from the English Quality and Outcomes Framework and the national GP Patient Survey. Ann Fam Med 2013;11:467-72.

11. Browne $\mathrm{K}$, Roseman D, Shaller D, et al. Measuring patient experience as a strategy for improving primary care. Health Aff 2010;29:921-5.

12. Picker Institute Europe. Improving patient experience. 2011. http:// www.pickereurope.org/improvingpatientexperience (accessed 21 Nov 2014).

13. Barnett K, Mercer SW, Norbury M, et al. Epidemiology of multimorbidity and implications for health care, research, and medical education: a cross-sectional study. Lancet 2012;380:37-43.

14. Guthrie B, Payne K, Alderson $P$, et al. Adapting clinical guidelines to take account of multimorbidity. BMJ 2012;345:e6341.

15. Mercer SW, Guthrie B, Furler J, et al. Multimorbidity and the inverse care law in primary care. BMJ 2012;344:e4152.

16. The King's Fund. Time to think differently: long-term conditions and multi-morbidity: The King's Fund, UK, 2012. http://www.kingsfund. org.uk/time-to-think-differently/trends/disease-and-disability/ long-term-conditions-multi-morbidity (accessed 21 Nov 2014).

17. Fortin M, Lapointe L, Hudon C, et al. Multimorbidity and quality of life in primary care: a systematic review. Health Qual Life Outcomes 2004;2:51.

18. Menotti A, Mulder I, Nissinen A, et al. Prevalence of morbidity and multimorbidity in elderly male populations and their impact on 10-year all-cause mortality: the FINE study (Finland, Italy, Netherlands, Elderly). J Clin Epidemiol 2001;54:680-6.

19. Vogeli C, Shields A, Lee T, et al. Multiple chronic conditions: prevalence, health consequences, and implications for quality, care management, and costs. J Gen Intern Med 2007;22:391-5.

20. Payne RA, Abel GA, Guthrie B, et al. The effect of physical multimorbidity, mental health conditions and socioeconomic deprivation on unplanned admissions to hospital: a retrospective cohort study. CMAJ 2013;185:E221-8.

21. Morris RL, Sanders C, Kennedy AP, et al. Shifting priorities in multimorbidity: a longitudinal qualitative study of patient's prioritization of multiple conditions. Chronic IIIn 2011;7:147-61.

22. Fung $\mathrm{CH}$, Setodji CM, Kung FY, et al. The relationship between multimorbidity and patients' ratings of communication. J Gen Intern Med 2008;23:788-93.

23. Bower P, Hann M, Rick J, et al. Multimorbidity and delivery of care for long-term conditions in the English National Health Service: baseline data from a cohort study. J Health Serv Res Policy 2013;18 (2 Suppl):29-37. 
24. France EF, Wyke S, Gunn JM, et al. Multimorbidity in primary care: a systematic review of prospective cohort studies. BJGP 2012;62: e297-307.

25. Campbell SM, Reeves D, Kontopantelis E, et al. Effects of pay for performance on the quality of primary care in England. NEJM 2009;361:368-78.

26. Kontopantelis E, Roland M, Reeves D. Patient experience of access to primary care: Identification of predictors in a national patient survey. BMC Fam Pract 2010;11:61.

27. The King's Fund. Improving the quality of care in general practice: report of an independent inquiry commissioned by The King's Fund, 2011. http://www.kingsfund.org.uk/sites/files/kf/improving-quality-ofcare-general-practice-independent-inquiry-report-kings-fund-march2011_0.pdf (accessed 21 Nov 2014).

28. Department of Health. Chief executives' report to the NHS. 2005. http://webarchive.nationalarchives.gov.uk/20080729050526/dh.gov. uk/en/Publicationsandstatistics/Publications/PublicationsPolicy AndGuidance/DH 4124276 (accessed 21 Nov 2014).

29. Department of Health. The NHS Outcomes Framework 2011/12. http:// www.dh.gov.uk/en/Publicationsandstatistics/Publications/

PublicationsPolicyAndGuidance/DH_122944 (accessed 21 Nov 2014).

30. Ipsos MORI. Technical Annex for the GP Patient Survey. https://gppatient.co.uk/surveys-and-reports (accessed 21 Nov 2014).

31. Paddison C, Elliott M, Parker R, et al. Should measures of patient experience in primary care be adjusted for case mix? Evidence from the English General Practice Patient Survey. BMJ Qual Saf 2012;21:634-40.

32. Full survey available online. https://gp-patient.co.uk/surveys-andreports (accessed 21 Nov 2014).

33. Department of Health. GP Patient Survey-over all practice report. https://gp-patient.co.uk/surveys-and-reports (accessed 21 Nov 2014).

34. Department for Communities and Local Government. The English indices of deprivation.

35. Dolan P. Modeling valuations for EuroQol health states. Med Care 1997;35:1095-108.

36. Higashi T, Wenger NS, Adams JL, et al. Relationship between number of medical conditions and quality of care. NEJM 2007;356:2496-504.

37. Fortin M, Stewart M, Poitras ME, et al. A systematic review of prevalence studies on multimorbidity: toward a more uniform methodology. Ann Fam Med 2012;10:142-51.
38. Mujica-Mota RE, Roberts M, Abel G, et al. Common patterns of morbidity and multi-morbidity and their impact on health-related quality of life: evidence from a national survey. Qual Life Res 2014 doi:10.1007/s11136-014-0820-7 [Epub ahead of print].

39. Brilleman SL, Salisbury C. Comparing measures of multimorbidity to predict outcomes in primary care: a cross sectional study. Fam Pract 2013;30:172-8.

40. Roland M, Elliott M, Lyratzopoulos G, et al. Reliability of patient responses in pay for performance schemes: analysis of national General Practitioner Patient Survey data in England. BMJ 2009;339: b3851.

41. Groves RM, Peytcheva E. The impact of nonresponse rates on nonresponse bias-a meta-analysis. Public Opin Q 2008;72: 167-89.

42. Krosnick JA, Presser S. Question and questionnaire design. In Marsden PV, Wright JD, eds. Handbook of survey research. 2nd edn. Bingley, UK: Emerald, 2010:263-313.

43. Seltzer SF, Yarczower M. Selective encoding and retrieval of affective words during exposure to aversive-stimulation. Pain 1991;47:47-51.

44. Kuhajda MC, Thorn BE, Klinger MR. The effect of pain on memory for affective words. Ann Behav Med 1998;20:31-5.

45. Roland M, Paddison C. Better management of patients with multimorbidity. BMJ 2013;346:f2510.

46. Tinetti ME, Bogardus ST Jr, Agostini JV. Potential pitfalls of diseasespecific guidelines for patients with multiple conditions. NEJM 2004;351:2870-4.

47. Sinnott C, Mc Hugh S, Browne J, et al. GPs' perspectives on the management of patients with multimorbidity: systematic review and synthesis of qualitative research. BMJ Open 2013;3:e003610.

48. Boyd CM, Darer J, Boult C, et al. Clinical practice guidelines and quality of care for older patients with multiple comorbid diseases: implications for pay for performance. JAMA 2005;294:716-24.

49. Gallacher K, Morrison D, Jani B, et al. Uncovering treatment burden as a key concept for stroke care: a systematic review of qualitative research. PLoS Med 2013;10:e1001473.

50. May C, Montori $\mathrm{V}$, Mair F. We need minimally disruptive medicine. BMJ 2009;339:b2803

51. Kerr EA, Heisler M, Krein SL, et al. Beyond comorbidity counts: how do comorbidity type and severity influence diabetes patients treatment priorities and self-management. J Gen Intern Med 2007;22:1635-40. 